\title{
Research on the Development Status, Problems and Countermeasures of Digital Finance in China
}

\author{
Bin Wang ${ }^{1, *}$ Xi Wang ${ }^{2}$
}

\author{
${ }^{1}$ Yunnan University of Finance and Economics, Kunming, Yunnan 650221, China \\ ${ }^{2}$ Guizhou University, Guiyang, Guizhou 550025, China \\ *Corresponding author. Email: gzshehuiwb@126.com
}

\begin{abstract}
With the rapid development of digital technology, China's digital finance keeps making new breakthroughs, but at the same time, the hidden risks of China's digital finance keep accumulating. Based on the analysis of the development status of digital finance in China, this paper explores the main problems in the development of digital finance in China. Accordingly, it puts forward corresponding countermeasures and suggestions.
\end{abstract}

\section{Keywords: digital economy, inclusive finance, development status}

\section{INTRODUCTION}

Digital finance refers to the use of digital technology by traditional financial institutions or Internet companies to carry out financing and other financial services. It is the combination of Internet finance and fintech. Digital finance uses modern digital information technology to reduce the cost of financial services, expand the coverage of financial services, and enhance the convenience of financial services. With the advent of the digital age, traditional financial institutions empower themselves by using digital technology. In this way, they accelerated the speed of transformation and upgrading, realized the effective connection between financial supply and demand, and improved the allocation efficiency of financial services. China's digital finance has basically formed the typical modes including bank mode, e-commerce mode, operator mode, social mode and searching mode. With the continuous innovation of science and technology, digital technology will further optimize the way of financial services, and the promotion of mobile phones and the Internet will provide more opportunities for financial services for the long tail group, so the digital financial industry will have greater development space in the future.

\section{THE DEVELOPMENT STATUS OF DIGITAL FINANCE IN CHINA}

The development of China's digital finance can be traced back to the launch of Alipay in 2004. After only a dozen years, China's digital finance has made many new breakthroughs. In November 2017, five of the top 10 fintech companies in the world were from China. China's mobile payment transactions reached 10.9 billion yuan in 2017. As of June 2018, the number of active mobile payment users reached 507.16 million. Mobile payment can not only provide basic financial services for financial consumers, but also provide big data support for inclusive finance. On Aug. 18, 2019, China proposed to support innovative applications such as digital currency research and mobile payments in Shenzhen. However, there are still many difficulties in the development of digital finance in China. To this end, while innovating digital financial regulation, China has also set up a digital financial reform pilot zone to explore a new path for the development of China's digital finance. In February 2020, China accelerated the construction of Shanghai International Financial Center and provided financial support to the integrated development of the Yangtze River Delta, actively promoted the pilot digital finance of Lin-gang Special Area of the Shanghai Pilot FTZ, and explored the application of block chain and other new technologies in the financial field.

The biggest advantage of China's digital finance is to accelerate the realization of inclusive finance. Since 2006, the Chinese government has taken a series of measures to promote the development of inclusive finance. For example, financial institutions are required to set up inclusive finance divisions and pilot "tworights" mortgages in rural areas (the "two rights" refer to the management right of contracted land and farmers' housing property right in rural areas), but there is always a lack of commercial sustainability. Digital technology provides solutions for this. On the one hand, the Internet tightly sticks to tens or even hundreds of millions of mobile terminals through various applications. On the other hand, big data technology is used to realize customer credit evaluation, which greatly reduces the cost of risk control. 


\section{MAJOR PROBLEMS FACING THE DEVELOPMENT OF DIGITAL FINANCE IN CHINA}

\section{A. The risks are pervasive}

Digital finance meets the financing needs of small and medium-sized enterprises. However, the financial quality of practitioners of small and medium-sized enterprises is generally low, and they tend to follow blindly, with the mentality of pursuing profits quickly, which increases the possibility of bank runs. So there is a risk of liquidity. In addition, in the digital financial model, it is difficult to evaluate customers' credit through "face-to-face", interaction and the understanding of customers' credit status is not comprehensive. Investors in digital finance have loan relationships with high-risk borrowers when not knowing the credit status of borrowers in order to pursue profit maximization, thus easily causing credit risks. As the regulatory policies of digital finance continue to improve, the business process and operation mode of digital finance will become more standardized, and some digital financial enterprises with poor qualifications will withdraw from the market, and the overall profit space of digital financial enterprises will be compressed. Therefore, there are policy risks.

\section{B. The financial supervision mechanism is not sound}

Digital finance is characterized by self-management and decentralization, which brings many challenges to financial regulation. At present, China's digital finance regulatory system is not sound, reflected in the following two aspects. First, there are phenomena like supervision absence and regulatory gaps in China's digital financial regulatory mechanism. As a result, some digital financial enterprises carry out regulatory arbitrage through innovative financial products and services, which is not conducive to the sustainable and healthy development of China's digital financial industry. Second, some digital financial enterprises have poor supervision technology, which makes their own supervision not effective and has some problems such as inadequate supervision.

\section{Digital infrastructure needs to be strengthened}

The development of digital finance needs to rely on the support of modern information technology, computer technology and network technology. The overall payment process and the liquidation process are relatively complex. At present, the development of digital finance in China is facing great challenges in the construction of digital infrastructure, which not only requires relatively large capital costs, but also has relatively high requirements for infrastructure construction. This asks for dynamic management following the development of industry and society.

\section{Financial literacy needs to be improved}

Digital finance requires participants to have higher financial literacy. At present, the financial literacy of participants in China's digital finance has the following problems. First, the financial literacy of employees in China's financial institutions is not high. As providers of digital financial services, most employees in Chinese financial institutions do not have standard professional ethics, and their knowledge system is updated on a relatively slow basis. Second, the financial literacy of the clients of Chinese financial institutions is generally low. The majority of digital financial consumers in China lack professional financial knowledge and have a weak ability to invest with digital technology.

\section{COUNTERMEASURES AND SUGGESTIONS ON THE DEVELOPMENT OF DIGITAL FINANCE IN CHINA}

\section{A. Further improving relevant laws and regulations on digital finance}

At present, relevant laws and regulations on digital finance in China are not perfect. Therefore, on the one hand, the existing financial laws and regulations should be revised and normative provisions related to digital finance should be added to adapt to the development characteristics of digital finance. On the other hand, laws and regulations specifically targeted at digital finance should be introduced to increase penalties for violations of laws and regulations in the field.

\section{B. Improving the digital financial credit investigation system}

The construction of credit investigation system is very important to the healthy development of digital finance. At present, the improvement of China's digital financial credit system should start from the following aspects. On the one hand, standards for user credit data collection should be set to expand the scope of data collection. The credit department should establish a unified standard for the collection of credit data, make full use of big data technology, and strengthen the collection and integration of all kinds of data. On the other hand, it is necessary to strengthen credit investigation supervision and maintain data security. Attention should be paid to the quality of data collection and the credit market access and exit mechanism should be improved.

\section{Building a digital financial "Regulatory Sandbox"}

In line with the development trend of financial innovation and the financial supervision system in China, it is necessary to establish a digital financial "Regulatory Sandbox" to strike a balance between innovation and risk prevention and control. The first is to establish a dynamic adjustment mechanism of rules 
in "Regulatory Sandbox". The concept of rule-based supervision should be introduced, and special personnel should be assigned to follow up and guide to improve the level of discretion. The second is that pilot projects should be carried out in the banking industry. The pilot projects should first carried out in the banking sector with the strongest risk control capability, and then gradually extended to other financial institutions with the continuous improvement of the financial regulatory coordination mechanism. The third is to protect the rights and interests of digital financial consumers. It is necessary to strengthen the protection of the rights and interests of digital financial consumers, focusing on their right to know, free choice and claim compensation in accordance with the law.

\section{Strengthening publicity and education on digital financial inclusion}

On the one hand, a training mechanism for financial practitioners should be established. It is necessary to strengthen the training of financial practitioners, help them build a digital financial professional knowledge system, and constantly improve their ability to serve the society. On the other hand, the propaganda and education of digital financial consumers should be strengthened. It is necessary to popularize the knowledge related to digital finance through the Internet, television, radio, newspapers and other means so as to improve the risk identification and selfprotection ability of digital financial consumers.

\section{E. Accelerating innovation in digital technology}

Digital finance enhances the enabling effect of digital technology innovation on finance, expands the coverage of financial services, and increases the effective supply of finance. The first is to strengthen the innovation of data collection technology. The information collection technology system should be established to strengthen the technology of data collection, input, summary, application and management, so as to improve the ability of original data acquisition and processing. The second is to strengthen the innovation of data mining technology. A technology system for intelligent processing and analysis of big data should be built to strengthen the research and development of artificial intelligence, block chain, big data and other technologies, and improve data processing capacity. The third is to strengthen innovation in information services. It is necessary to construct data management technology system to accelerate the digitization process of industry management and service process.

\section{F. Strengthening international exchanges and cooperation in digital finance}

On the one hand, advanced digital financial management concepts and data modeling technology should be introduced from developed countries. On the other hand, it is necessary to actively participate in the formulation of international digital finance rules and hold the right of speech, so as to gradually improve the international competitiveness of China's digital finance.

\section{CONCLUSION}

Digital finance refers to the use of digital technology by traditional financial institutions or Internet companies to carry out financial services such as investment and financing, which is the combination of Internet finance and fintech. Digital finance can accelerate the innovative development of traditional finance, improve the efficiency and level of financial services to the real economy, and realize the effective connection between financial supply and demand. At present, China's digital finance is developing rapidly, but there are some problems, such as imperfect financial supervision mechanism, incomplete digital financial infrastructure, and the need to improve financial literacy. Therefore, it is suggested to further improve relevant laws and regulations of digital finance, improve the credit investigation system of digital finance, establish "Regulatory Sandbox" to prevent digital financial risks, strengthen the publicity and education of digital GSP, accelerate digital technology innovation, and strengthen international exchanges and cooperation of digital finance.

\section{References}

[1] Xuan Changneng. China's First Financial Sector Evaluation Plan Was Successfully Completed [J]. China Finance, 2012(19): 40-42. (in Chinese)

[2] Wang Xin. A Study on Internet Finance Helping Relieve SMEs Finanacing Constraints [J]. Journal of Financial Research, 2015(09):128-139. (in Chinese)

[3] Song Xiaoling. Research on the Impact of China's Digital Inclusive Financial Development on Narrowing the UrbanRural Income Gap [J]. Journal of Financial Science, 2017(06): 14-25. (in Chinese)

[4] Research group of the Digital Finance Research Center, Peking University. Practice of Digital Inclusive Finance in China Beijing: China Renmin University Press, August 2017. (in Chinese)

[5] Hao Yunping, Lei Hanyun. Is Digital Inclusive Finance Driving Economic Growth? $[\mathrm{J}]$. Journal of Contemporary Financial Research, 2018 (03): 90-101. (in Chinese)

[6] Huang Yiping, Huang Zhuo. The Development of Digital Finance in China: Present and Future [J]. China Economic Quarterly, 2008, 17(04): 1489-1502. (in Chinese)

[7] Wang Jiao, Wang Wenrong, Ma Guoweng, Wang Ziyu. Research on the Application of Digital Technology to Promote the Development of Inclusive Finance in Urban and Rural Areas [J]. Agricultural Economy, 2019(11): 126-127. (in Chinese)

[8] He Hongqing. Digital Finance: an Important Driver of Highquality Economic Development [J]. Journal of $\mathrm{Xi}^{\text {‘ }}$ an Institute of Finance \& Economics, 2019, 32 (02): 45-51. (in Chinese)

[9] Wu Shandong. Risk Issues, Regulatory Challenges and Development Proposals of Digital Inclusive Finance [J]. Journal 
of Technical Economics \& Management, 2019(01): 66-69. (in Chinese)

[10] Li Ruixue, Yan Zhengxin. Research on the Development and Regulation of Intelligent Investment in Digital Inclusive Finance [J]. Price Theory \& Practice, 2019(09): 112-115. (in Chinese)

[11] Wei Xiaofeng. Digital Inclusive Finance: risk and regulation [J]. Financial Theory \& Practice, 2019(06): 49-54. (in Chinese)

[12] Zhang Xun, Wan Guanghua, Zhang Jiajia, He Zongyue. Digital Economy, Inclusive Finance and Inclusive Growth [J]. Economic Research Journal, 2019, 54 (08): 71-86. (in Chinese)

[13] Pan Xiquan. The Logical Mechanism and Implementation Mechanism of Digital Inclusive Finance to Help Low-income Groups [J]. Regional Economic Review, 2019(04): 143-149. (in Chinese)

[14] Li Haifeng, Peng Jiasheng, He Wei. Research on the Influence of Digital Financial Services on the Development of Inclusive Finance: Theoretical Basis and Empirical Evidence [J]. Journal of Southwest Minzu University (Humanities and Social Science), 2019, 40 (06): 139-145. (in Chinese)

[15] He Hongqing. Digital Finance: an Important Driver of Highquality Economic Development [J]. Journal of Xi'an Institute of Finance \& Economics, 2019, 32 (02): 45-51. (in Chinese)

[16] He Fei. Research on Digital Financial Models at Home and Abroad [J]. Rural Finance Research, 2019(06): 23-29. (in Chinese)

[17] Wu Shandong. Risk Issues, Regulatory Challenges and Development Proposals for Digital Financial Inclusion [J]. Journal of Technical Economics \& Management, 2019(01): 6669. (in Chinese)

[18] Lin Sheng, Bian Peng, Yan Han. A Comparative Study on the Policy Framework of Digital Inclusive Finance at Home and Abroad [J/OL]. Credit Reference, 2020(01): 78-82 [2020-0222].

http://kns.cnki.net/kcms/detail/41.1407.f.20191210.0937.028.ht ml. (in Chinese)

[19] Pang Yanbin. Digital Inclusive Finance Helps Rural Revitalization [J]. People's Tribune, 2020(01): 98-99. (in Chinese)

[20] Yu Ping, Dou Junxia. Has the Development of Digital Inclusive Finance Eased the Financing Constraints of SMEs [J/OL]. Finance and Accounting Monthly: 1-7 [2020-02-22]. HTTP: / / https://doi.org/10.19641/j.cnki.42-1290/f.2020.03.022. (in Chinese)

[21] Dong Yufeng, Chen Junxing. Poverty Reduction Through Digital Inclusive Finance: Theoretical Logic, Model Construction and Promotion Path [J/OL]. South China Finance: 1-9 [2020-02-22]. http://kns.cnki.net/kcms/detail/44.1479.F.20200120.1643.008.ht ml. (in Chinese)

[22] Huang Zhaohui, Huang Jiaqing, Li Shumin. Empirical Analysis on the Support of Internet Supply Chain Finance to China's Commercial Circulation Industry $[\mathrm{J}]$. Journal of Commercial Economics, 2020(04): 162-165. (in Chinese) 